\title{
ОБ УСЛОВИЯХ ФОРМИРОВАНИЯ ОБЩЕПРИЗНАННЫХ НОРМ
}

\author{
Ю.C. Р о м а ш о в*
}

Важную регулирующую роль в межгосударственньх отношениях играют общепризнанные нормы мехдународного права. В связи с этим, задача определения условий, при которьх нормы международного права приобретают статус "общепризнанньх", имеет как теоретическую, так и практическую значимость. Актуальность этой задачи усиливается положением ст.15 Конституции Российской Федерации, в соответствии с которой общепризнанные принципы и нормы международного права, международные договоры Российской Федерации, являются составной частью ее правовой системы. Указанная задача, как проблемная, была отмечена видными учеными И.И. Лукашуком и С.А. Малининым на первой в России региональной конференции Ассоциации международного права, состоявшейся в сентябре 1997 года в г. Москве. Проблема определения условий "общепризнанности" норм международного права вновь прозвучала в ноябре 1998 г. в г. Москве на международной конференции "Международно-правовые проблемы Мирового океана".

Существует много мнений среди ученьх и практических работников об этих условиях “общепризнанности". Например, существует точка зрения, что для данного случая приемлема ситуация, когда обычная норма должна быть признана всеми или почти всеми государствами ${ }^{1}$. Лукашук И.И. отмечает, что все нормы общего международного права принимаются и изменяктся мехдународным сообществом государств в целом. Причем требование принятия нормы международньп сообществом в целом не означает полного согласия его членов, а имеется в виду достаточно представительное большинство. И.И. Лукашук, анализируя наиболее часто высказываемые учеными различных государств мнения о критериях большинства, приводит следуюшие

* Кандидат военньх наук. Член Российской ассоциации международного права, Российской ассоциации морского права, Криминологической ассоциации, академик Мехдународной ахадемии информатизации. Имеет более 100 научньх трудов по различньм проблемам международного права, погранологии, борьбы с преступностью на море. Участвовал в разработке проектов федеральньх законов в группе зкспертов Государственной Думы: "О континентальном шельфе Российской Федерации”, “Об исключитетьной экономической зоне Российской Федерации", "О борьбе с терроризмом", “Об оружии". 
его характеристики: "преобладающее большинство”, "оно должно включать все крупнейшие державы”, “требуется учет не только размеров государства, но и объема его международных связей и вообще его вклада в развитие международного права". При этом он отмечает, что все эти критерии имеют определенное политическое, но не правовое значение, поскольку они не соответствуют принципу суверенного равенства. И.И. Лукашук сам отдает предпочтение точке зрения, согласно которой большинство должно быть достаточно представительным не только в количественном, но и в качественном отношении, представляя, по крайней мере, все основные политические, социально-экономические и правовые системы, а также все континенты. К ним он добавляет еще один немаловажный критерий, заключающийся в том, что когда создается норма, имеющая большое значение для определенньх государств в силу специфики их положения, то общая практика должна включать практику таких государств².

Заслуживают большого внимания и учета при решении вопроса "общепризнанности" норм международного права мнения многих других ученьх, которые также указывают, что в основу решения данного вопроса могут быть положены как качественные, так и количественные критерии. Вместе с тем, несмотря на то, что приведенные выше доводы позволяют сделать общий вывод о том, что условием общепризнанности норм международного права не обязательно является их признание всеми государствами, это условие так и не было конкретизировано. То есть, не было уточнено количество государств и их возможный состав, при признании обычной нормы которьми наступает условие ее “общепризнанности". Важно в связи с этим отметить, что международное право не может развиваться и решать встающие перед обшеством сложные проблемы, не объединив знания общественньх, естественньх, технических наук, без их взаимодействия. Именно на стыке различных наук появляются наиболее полноценные исследования как фундаментального, так и прикладного характера. Интеграция, слияние, объединение различных наук в комплексном исследовании соответствующих проблем приводит к их решению. Рассматриваемый же вопрос, при отсутствии такого подхода, будет стоять вечно, всегда вызывать споры, если подходить к нему только с интуитивных позиций, хотя, как показывает практика, и не всегда ошибочньх. Основываясь на этом, автор для решения данного вопроса предлагает использовать приведенную ниже методику, основанную на использовании как качественных, так и количественньх методов исследования. Сразу необходимо отметить, что излагаемьй 
подход не является единственно возможным. Автор, прежде всего, хотел бы привлечь внимание к использовиию в целях решения рассматриваемой проблемы как качественных, так и количественньх критериев.

Для определения условий, при которых обычная норма становится "общепризнанной", необходимо построить модель, с помощью которой можно получить требуемые рекомендации. В нашем случае задача состоит в определении такого порога (критерия), соответствующего минимально необходимому количеству государств, признавших обычную норму, и составу этих государств, при достижении которого эту норму мохно считать "общепризнанной". Тем самым мы уточняем, что подразумевается под фразой "почти все". Важно отметить, что сама оценка фраз "Почти все государства", "большинство государств" уже свидетельствует о том, что некоторые государства могут быть не согласны с ее положениями по каким-либо объективным или субъективным причинам, и не признавать норму. При этом, "если отдельное государство не согласно с обычной нормой, принимаемой представительньм большинством, то оно должно настойчиво и последовательно протестовать" в дальнейшем позишия этого государства может быть и смятена. Следовательно, для определения условий “обепризнанности" необходимо производить качественный и количественный анализ состава посударств, участвуюших в нормотворческом процессе. С этой целью целесообразно выбрать количественные и качественные критерин, а также соответствуюшие им показатели, которые должны быть положены в онову построения указанной модели. При их выборе, по мнению автора, должны учитываться: природа и характер рассматриваемой международно-правовой нормы, предметная область, которую она затрагивает; принцип суверенного равенства государств; роль, которую играет та или иная международная норма в жизни конкретного государства, в регулировании межтосударственных отношений друг с друтом. Здесь также уместно говорить и о "всеобщем" признании и применении государствами этой нормы, что, по мнению автора, должно предусматривать не только признание и применение нормы максимальным количеством государств, но и максимальньй охват нормой потенциальньг ее применителей в этих государствах, то есть охват нормой государств, интересы которьх она в максимальной степени затрагивает. Это отвечает положению ст.38 Статута Международного Суда о международном обычае как доказательстве всеобщей практики, признанной в качестве правовой нормы.

Сразу необходимо указать на то, что в зависимости от содержания норм, по мнению автора, могут рассматриваться два 
основных подхода для решения задачи “общепризнанности". Первый, когда норма регулирует межгосударственные отношения, имеющие всеобщий характер, т.е. когда она в равной мере затрагивает интересы государств (ответственность государств, права человека и др.). Второй, когда норма регулирует межгосударственные отношения в какой-либо специфической области и ей абстрактно можно поставить в соответствие некоторый числовой показатель (потенциал). Этот показатель должен соответствовать предметной области, которую затрагивает данная норма, а его значение характеризовать применение государствами этой нормы, то есть ту роль, которую она играет в жизни государств.

Первый подход весьма характерен для случая, когда норма становится "общепризнанной", если ее признали "все” государства, хотя, как уже ранее указывалось, это не бесспорно и необходимо говорить "почти все государства", "большинство государств", указав на число государств и их состав. В этом случае, когда норма одинаково затрагивает интересы государств, в той или иной области, по мнению автора, сложно говорить о каких-либо количественньх выпладках, и здесь довольно сложно уйти от субъективньх оценок. Поэтому мировое сообщество должно само определиться, какое количество государств должно признать норму, чтобы она стала общепризнанной, обязательной для всех.

Подобньми критериями могут стать столь часто применяемые количественные показатели "большинства" - 1/2, 2/3, $3 / 4$ или большая часть от какой-либо числовой характеристики. В нашем случае, это некоторая часть от общего количества государств, без указания на какие-либо качественные характеристики состава государств. В то же время, здесь не исключено использование, наряду с количественньми характеристиками, и качественньх характеристик состава государств, не противоречаших принципу суверенного равенства государств. Например, можно использовать приведенные выпе качественные характеристики, на которые указал в своих трудах И.И. Лукашук. В качестве научного метода здесь целесообразно использовать метод экспертньх оценок, который мог бы быть осуществлен при проведении опроса по данной теме среди наиболее квалифицированных специалистов по мехдународному публичному праву.

Организационно данный опрос можно было бы провести, например, во время очередной конференции Ассоциации международного права, среди ее участников, являющихся наиболее квалифицированными специалистами. Результаты опроса могли бы быть оформлены в виде решения и тем самым в дальнейшем послужить в качестве вспомогательного средства для определе- 
ния общепризнанньх норм международного права. Подобный критерий мог бы вполне обоснованно использоваться Международным Судом ООН при решении дел, входящих в его компетенцию. Указанный вопрос, по мнению автора, мог бы быть решен и в рамках ООН путем проведения экспертного опроса среди представителей государств-членов этой международной организации на одной из сессий Генеральной Ассамблеи ООН с последуюшим закреплением его результатов в соответствующей резолюции. В то же время, необходимо подчеркнуть, что подобным образом принятые критерии не носят для государств юридически обязательной силы, а имеют лишь вспомогательный характер. Могут быть и другие варианты закрепления результатов подобного опроса, вплоть до принятия критериев "общепризнанности" в договорной форме. Решение данного вопроса имеет принципиальное значение для мирового сообщества, для повьшения эффективности международно-правового регулирования, а поэтому требует безотлагательного рассмотрения.

В то же время большинству норм мехдународного права, которые в разной мере затрагивают интересы государств, то есть находят в этих государствах и в их отношениях между собой различное применение, все же можно абстрактно поставить в соответствие некоторьй количественньй показатель, который позволяет учесть эти обстоятельства. В качестве примера определения условий "общепризнанности" обычньх норм, регулирующих какую-либо специфическую область межтосударственньх отношений, рассмотрим область мехдународного морского права и характеризуюшие эту область показатели. Например, торговый флот государства, может характеризоваться такими показателями, как количество судов, их суммарный тоннаж, а также рядом других показателей. Этот флот осуществляет определенный грузооборот на море в интересах как отдешньх государства, так и в системе международного разделения труда. Величина этого грузооборота в свою очередь характеризует конкретное государство в экономической области. Государство может иметь и определенной численности рыболовньй, пассажирский, научно-исследовательский флоты, военно-морской флот и друтие морские силы, также итрающие определенную роль как внутри государства, так и в межгосударственньх отношениях.

В связи с этим норма международного права, регулирующая тот или иной вид межтосударственньх отношений, может иметь разное количествп правоприменителей в этих государствах, a, следовательно, в различной мере затрагивать интересы каждого из них. Некоторые нормы международного права могут порой и не иметь никакой правоприменительной практики в отдельньх 
государствах, в их отношениях с другими государствами, или могут в незначительной мере затрагивать их интересы. Следовательно, практика применения государствами конкретной нормы международного права может характеризоваться различными количественньми показателями, которые могут учитываться при определении условий их "общепризнанности".

Выбор конкретных показателей для решения указанной задачи в каждом случае должен основываться на анализе предметной области, которую затрагивает норма. Например, если норма затрагивает экономическую область в деятельности государств (нормы, регулируюшие отношения в сфере экономической деятельности государств на море), то целесообразно выбирать некоторый экономический потенциал, например, тоннаж судов, грузооборот, предполагаемый доход, убытки и т.д. Если норма затрагивает деятельность всех судов государств, как отдельных единиц (нормы, регулируюшие вопросы борьбы с незаконными актами, направленными против безопасности морского судоходства, в целом вопросы безопасности судоходства и пр.), то в качестве показателя целесообразно выбирать количество морских судов, приходящееся на различные государства. Важно отметить, для нахождения искомого критерия могут использоваться несколько показателей, рассматриваемьх в качестве главньх и частных (промежуточных).

Определив показатель, необходимо установить искомую зависимость мехду государствами и значением этого показателя (потенциалом), а также уточнить критерий, при котором наступает условие "общепризнанности" норм. Автором была проанализирована зависимость мехпу 166 государствами, имеющими морские флоты, и потенщиалом, представленным количеством судов, плавающих под флагом этих государств. С этой целью производилось ранжирование государств в соответствии с убыванием значения выбранного показателя, то есть потенциала. При уточнении с указанной целью количества и состава государств автор стремился "исключить" из общего числа государства только те из них, которые обладают незначительньм потенциалом и их влияние на производимую оценку незначительно. Здесь важко подчеркнуть, что подобное "исключение" никоим образом не покушается на принцип суверенного равенства государств. Этот приншип здесь полностью соблюдается. Автор, прежде всего, пытается уточнить миниматьно необходимое число государств, то есть уровень, при достижении которого наступает условие "обшепризнанности". Также автор пытается определить и качественный состав государств, удовлетворяющий требованию "всеобщей практики". 
В качестве вспомогательного критерия, которьй может быть использован при определении условия "общепризнанности" норм международного права, автор предлагает использовать среднее значение потенциалов всех государств (в нашем примере, среднее количество судов, приходящееся на одно государство, прим. автора). Использование этого критерия позволяет учитывать потенциальные возможности государств в применении данной нормы, при максимально возможном учете требования "всеобцей практики" и принципа суверенного равенства государств. При этом само условие “общепризнанности" наступает, когда значение приращения суммарного потенщиала отдельньх государств, ранжированных в указанном порядке, равно или превьпшает значение, принятого нами порогового значения, выбранного в хачестве вспомогательного критерия.

Результаты проведенного анализа показали, что число государств, влияние которьх на производимую оценку незначительно, в нашем случае составляет 44 из 166 государств $(26,6 \%)$. Таким образом, было определено минимально необходимое число государств (122) и их состав, интересы которых в наибольшей мере затрагиваются применением обычной нормы. При признании этими государствами указанных норм, их, по мнению автора, можно было бы считать "общепризнанными".

В то же время, необходимо отметить, что в проведенной выше оценке соблюдалось условне участия всех государств потенциальньх применителей норм международного права. Реально же, как мы уже выше отмечали, не все государства участвуют в нормотворческом процессе, не все признают отдельные нормы, имея иную практику, чем предусмотрена в этих нормах. Кроме того, по мнению автора, необходимо ослабить влияние государств, которые характеризуются значительным потенциалом, на процесс формирования общепризнанных норм мехдународного права. Это необходимо для того, чтобы непризнание ими норм международного права не было решающим для условий их "общепризнанности". С этой целью необходимо одновременно испальзовать и подход, который былі предложен автором при рассмотрении первого случая. Важно отметить, что первый случай являелся частным случаем второго и соответствует ситуации, когда потенциалы государств равны друг другу.

Такям образом, основываясь на изложенных выше в качестве общей формулировки условиях, при которьх обычную норму мехдународного права можно считать "общепризнанной", можно предложить "признание обычной нормы международного права большинством государств (установленным мировым сообществом, прим. автора), интересы которьх в наибольшей мере затра- 
гиваются применением этой нормы”. В качестве непременного условия должно быть соблюдено требование к обычной норме международного права, в части, касающейся "всеобщей практики”, как первом основании ее создания. При уточнении состава государств, интересы которьх в наиболњшей мере затрагиваются этой нормой, и при установлении минимально необходимого большинства из них, может быть испољзован подход, предложенный автором. В то же время автор не исключает использование и друтих подходов $\mathrm{K}$ определению качественного и количественного состава этих государств, которые ранее были предложены другими ученьми. Но эти подходы, по мнению автора, должны иметь под собой как качественное, так и количественное обоснование. Также желательно, чтобы предложенные ими условия "общепризнанности" норм международного права имели правовое закрепление, чтобы исключить их произвольное толкование.

Предложенная модель определения условий "общепризнанности" норм международного права, благодаря ее простоте, может найти широкое применение в правоприменительной практике государств, в практике деятельности ООН и других международных организаций, а также Международного Суда ООН при рассмотрении переданньх ему дел. При этом в качестве потенциалов могут выбираться и другие количественные показатели, например численность населения, площадь территории, различные экономические показатели и т.д. Но важно здесь подчеркнуть, что это касается случая, когда обычная норма регулирует межтосударственные отношения в какой-либо специфической области и этой норме можно абстрактно поставить в соответствие некоторую количественную характеристику. С этой целью весьма актуально формирование банка данньх указанных показателей как исходньх параметров, необходимьх для моделирования с целью определения условий "общепризнанности" конкретньх норм международного права. Теоретическое и практическое значение предложенной модели заключается еще и в том, что с ее помощњю можно анализировать процесс формирования общепризнанньх норм международного права и соответственно анализировать процесс эффективности международно-правового регулирования в различньх сферах международного сотрудничества.

Важно отметить, что предложенная модель, с помошью которой можно уточнить условия "общепризнанности" норм международного права, является несколько упрошенной. В то же время она с достаточной для практикн точностью позволяет довольно быстро получать необходимые рекомендации. Особенно эта задача облегчается с использованием ПЭВМ. Автор не исключает, 
что указанная модель может получить дальнейшее развитие и уточнение в отдельном исследовании, в болышей части математической направленности, так как юридическая постановка задачи (начальные параметры и условия, основные подходы) на разработку модели автором произведена выше.

Предложенный подход может быть использован и с целью уточнения условий, при которых международные нормы и стандарты становятся "общепринятыми". Подобная характеристика наиболее часто встречается, например, в Конвенции ООН по морскому праву 1982 г. и, видимо, будет все чаще встречаться в международньх договорах, нормы которых регулируют межтосударственные отношения в каких-либо специальных областях. Об этих условиях также существует много мнений среди ученьх и практиков. Но как отмечает в своих трудах К. Хакапаа, оцениваемые нормы и стандарты должны разрабатываться на широко признанной международной основе, а условия, предъявляемые $\mathrm{k}$ подобной оценке, могут быть не столь строгие. То есть минимальное число государств, поддерживаюших соответствующую международную норму или стандарт, может быть несколько меньшим, чем это необходимо для образования норм обычного права. По мнению этого ученого, иначе бы исчезло различие между обычными нормами и общепринятыми международными нормами и стандартами ${ }^{4}$. Также представляют интерес научные труды Г.Г. Иванова, который предлагает учитывать при производстве указанной оценки и количественные показатели, например такие, как тоннаж судов ${ }^{5}$. Все эти мнения могут быть учтены в предложенной автором модели, что свидетельствует об ее универсальности.

${ }^{1}$ См.: Международное право: Учебник/Под ред. Г.И. Тункина. - М., 1994. $-\mathrm{C} .60$.

2 См.: Л у к а ш у к И.И. Нормы международного права в международной нормативной системе. - М., 1997. - С. 236, 237.

${ }^{3}$ Л у к а ш у к И.И. Нормы международного права в международной нормативной системе. - М., 1997. - С. 239.

${ }^{4}$ См.: Х а к а п а а К. Загрязнение морской среды и международное право: Пер. с англ. В.А. Киселева/Под ред. и со вступит. ст. А.Л. Маковского. - М., 1986. - C. 128.

${ }^{5}$ См.: И в а н о в Г.Г. Международная морская организация. - М., 1994. С. 17; Иванов Г.Г. Роль Конвенции ООН по морскому праву 1982 г. в деятельности Международной морской организации (Тезисы)//Материалы международной конферендии "Международно-правовые проблемы Мирового океана". - М.: МИД России, Российская Ассоциация международного права, Ассоциация международного морского права, 1998. - С. 99.

Cтатья поступила в редакцию в декабре 1998 г. 